\title{
Effects of Hybrid Fibre Reinforcement on Fire Resistance Performance and Char Morphology of Intumescent Coating
}

\author{
N. Amir ${ }^{1, a}$, A. A. Abd. Majid ${ }^{1}$ and F. Ahmad ${ }^{1}$ \\ ${ }^{1}$ Mechanical Engineering Department, Universiti Teknologi PETRONAS, 32610 Bandar Seri Iskandar, Perak, Malaysia
}

\begin{abstract}
Recent researches of fire retardant intumescent coatings reinforced by single Rockwool and single glass wool fibre at various weight percentages and lengths showed some improvements to the mechanical properties of the coatings and the char produced. Therefore, in this research the fibres were combined together in intumescent coating formulation at several weight percentages and fibre lengths to study their effects towards fire resistance performance and char morphology. The hybrid fibre reinforced intumescent coatings were subjected to two types of fire tests; Bunsen burner at $1000^{\circ} \mathrm{C}$ and the electric furnace at $800^{\circ} \mathrm{C}$ for 1 hour, respectively. Steel temperature of the coated samples during Bunsen burner test was recorded to determine the fire resistance performance. Thermal stability of the intumescent coatings and chars was determined by Thermogravimetric Analysis (TGA). The morphology of the coatings and char was then examined by using Scanning Electron Microscopy (SEM) and Energy Dispersive Spectrometry (EDS) was conducted to obtain elemental composition of the samples. This research concluded that long-hybrid fibre at $12-\mathrm{mm}$ length and $0.6 \%$ fibre-weight produced the top performing hybrid fibre intumescent formulation. The hybrid fibres form survived at elevated temperature, hence helped to provide structure and strengthen the char with the highest fire resistance was recorded at steel temperature of $197^{\circ} \mathrm{C}$.
\end{abstract}

\section{Introduction}

There are mainly two types of fire protection; active and passive. Active fire protection is a prevention of fire and smoke spread out to allow a safe escape for building occupants. On the other hand, passive fire protection prevent building structure from serious damage and reduce the risk of collapse for the emergency services. Passive fireproofing materials can be defined as an insulation system to reduce heat transfer from fire to the structure being protected [1].

Fire retardant intumescent coating is categorized as passive fire protection. It is now, widely used in onshore and offshore industries to protect structural steel, walls and pipes from major failure [2]. Intumescent coating is inert at low temperature. It swells into thick, robust foam when exposed to high temperature and produce a protective char layer hence; underlying material is protected as it reduces the rate of temperature rise and extends the steel load bearing capacity [3].

Generally, intumescent coating is made up of three basic ingredients which are acid source, carbon source and blowing agent $[1,4]$. However, a traditional formulation of intumescent produced soft char and easily detached from the substrates, it is protecting. The char with low mechanical strength cannot protect base material effectively. Therefore, intumescent coating requires reinforcement materials so that the char strength can be increased [5].

There are a number of materials that already be used to externally reinforce intumescent coating, such as using of graphite fabric, wire mash or fiberglass fabric prior the application of the coating [6]. Recently, studies of intumescent coating reinforced by numerous single-type of fibre have shown improvements to fire resistance and char strength. Also reported are the effects of fibre length and fibre weight [5]. Therefore, this research is carried out to study the effects of length and weight percentage of hybrid fibre reinforcement (glass wool fibre and Rockwool fibre combinations) towards fire resistance of the coating as well as morphology of the char produced.

\section{Literature review}

\subsection{Fire retardant intumescent coating}

Intumescent can be defined as a process of getting to a swollen state. In flame retardant terminology, intumescent is a series of chemical and physical processes to swell and produce char when exposed to high temperature [4]. It is used to protect especially steel from extreme heat and fire effects [7].

Fire retardant intumescent coating covers wide range of applications such as aircraft carriers, construction

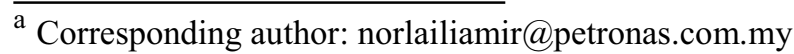


industry and oil and gas offshore platforms [3]. Its fundamental, according to Mount and Camino et al., to form a foam char, fire retardant intumescent should have three major parts, which are acid source as catalyst, a carbon rich polyhydric material as char former (carbonific) and a blowing agent, which is called spumific [4]. The char layer formed will protect the substrate material from fire.

Nonetheless, current intumescent coating poses several disadvantages such as lack of char strength, expensive and easily detach from the steel substrate [7]. Many studies concluded that to strengthen the char, intumescent coating need to be reinforced with suitable fillers and additives. A reinforced intumescent coating produced char having more compact cell structure and higher strength. Current researches included intumescent coating been reinforced with fibres such as Rockwool fibre, glass wool fibre, carbon fibre, glass fibre and ceramic wool fibre [7-8]. The growth of phosphorosilicate glass from glass fibre and glass wool fibre had improved insulation and the durability of intumescent coating's char [7].

\subsection{Glass wool fibre}

Glass wool fibre is an insulating material made from fiberglass into wool texture. It is synthetic or man-made, very small finely spun fibres of glass that form a mass resembling wool. They are commonly used for insulation or filtration because of thermal and acoustic properties, light weight, high tensile strength and exceptional resilience. Glass wool insulation is one of the most widely used forms of insulations world-wide. They consist of fine, long, inorganic fibres bonded together by high temperature binder. These fibres (each of approx. 6$7 \mu \mathrm{m}$ in diameter) are distributed to trap millions of tiny pockets of air in it for excellent thermal resistance [9].

Furthermore, glass fibre has high softening temperature. In this project of intumescent coating, as stated by Langer, glass fibre that is used is glass microfibers with a diameter less than $2.0 \mu \mathrm{m}$ in an amount from $0.1 \%$ to $5 \%$ by weight of total mixture. Using borosilicate glasses also could be considered [7].

\subsection{Rockwool fibre}

Rockwool fibre is amorphous synthetic mineral fibre made of combination of rock and sand. Then, both of them are together spun to make fibres [10]. It is a good conductor of heat individually but rolls and sheets of this insulation are highly efficient at blocking heat transfer. As Rockwool is non-combustible, it provides excellent thermal resistance [10]. Rockwool fibres are often used to prevent spread of fire in buildings, in light of their extremely high melting point.

In addition, Rockwool fibre reinforcement coating provides great fire protection as it effectively resists degradation up $800^{\circ} \mathrm{C}$. Furthermore, it contains more inert fillers which, yields more non-volatile compounds and residue to increase the thermal properties of the char [7]. Rockwool fibre has large diameter and was found crystallized at high temperature. Bigger-sized fibre normally produced more char and denser cell structure.

\section{Materials and methodology}

\subsection{Materials and formulations}

Ammonium polyphosphate (APP) was used as an acid source, melamine (MEL) as a blowing agent and expendable graphite (EG) as a carbon source were used as main ingredients of fire retardant intumescent coatings. Boric acid (BA) acts as a mineral acid. Bisphenol A epoxy resin BE-188 (BPA) was used to bind the formulations and polyaminamide (PA) was used as a hardener. Ratio of 3:1:1, was used as the ratio of the main ingredients; APP:MEL:EG [10].

Rockwool fibre and glass wool fibre was added to reinforce the coatings. 1 formulation was added with $0.3 \mathrm{~g}$ and $12 \mathrm{~mm}$ glass wool + Rockwool fibre, 2 formulations added with $0.6 \mathrm{~g}$ glass wool + Rockwool fibre with $8 \mathrm{~mm}$ and $12 \mathrm{~mm}$ fibre length respectively and 1 formulation added with $0.9 \mathrm{~g}$ and $8 \mathrm{~mm}$ glass wool + Rockwool fibre. $5 \mathrm{~cm} \times 5 \mathrm{~cm}$ and $10 \mathrm{~cm} \times 10 \mathrm{~cm}$ mild steel plates readily coated with primer coating, Dulux Epoxy-Zinc Phosphate with $1.0 \mathrm{~mm}$ thickness were used to be coated with the intumescent coating. The formulations prepared are shown in Table 1.

Table 1. Hybrid fibre reinforced intumescent coating formulations.

\begin{tabular}{|c|c|c|c|c|c|c|c|c|}
\hline \multirow{2}{*}{ No } & \multicolumn{5}{|c|}{ Ingredients (\%) } & \multicolumn{2}{|c|}{ GWF+RWF } \\
\cline { 2 - 9 } & BPA & PA & APP & EG & BA & MEL & $\begin{array}{c}\text { Wt. } \\
(\%)\end{array}$ & $\begin{array}{c}\text { Lt. } \\
(\mathbf{m m})\end{array}$ \\
\hline 1 & 43.45 & 21.73 & 11.76 & 5.5 & 11.76 & 5.5 & 0.3 & 12 \\
\hline 2 & 43.25 & 21.63 & 11.76 & 5.5 & 11.76 & 5.5 & 0.6 & 8 \\
\hline 3 & 43.25 & 21.63 & 11.76 & 5.5 & 11.76 & 5.5 & 0.6 & 12 \\
\hline 4 & 43.05 & 21.53 & 11.76 & 5.5 & 11.76 & 5.5 & 0.9 & 8 \\
\hline
\end{tabular}

\subsection{Sample preparation}

Initially, APP, MEL and BA were weighted according to TABLE 1 . by using electronic weighing scale and then grinded for three minutes in Rocklab mortar grinder. The grinded mixture was then added with EG and hybrid wool fibre which were initially cut. The mixture was then mixed with BPA by using Caframo mixer with 40rpm for 20 minutes. Hardener was then added and it was mixed again by the mixer with the same speed for 10 minutes. After that, the mixture was evenly applied onto primed $5 \mathrm{~cm} \times 5 \mathrm{~cm}$ and $10 \mathrm{~cm} \times 10 \mathrm{~cm}$ mild steel plate by using metal spatula. The coatings were left to be fully dried in room temperature for a week by natural drying process. The thickness of the coatings, were measured by using portable thickness gauge and vernier caliper.

Four different intumescent coating formulations have been coated onto different mild steel plates. The 
intumescent coatings prepared are labelled as shown in Table 2 .

Table 2. Hybrid fibre reinforced intumescent coating test pieces and their descriptions.

\begin{tabular}{|c|c|c|c|c|c|}
\hline No. & Label & $\begin{array}{c}\text { GWF } \\
\text { weight } \\
(\mathbf{\%})\end{array}$ & $\begin{array}{c}\text { RWF } \\
\text { weight } \\
(\mathbf{\%})\end{array}$ & $\begin{array}{c}\text { Total Fibre } \\
\text { weight (\%) }\end{array}$ & $\begin{array}{c}\text { Fibre } \\
\text { length } \\
\text { (mm) }\end{array}$ \\
\hline 1 & GRT3-2 & 0.15 & 0.15 & 0.3 & 12 \\
\hline 2 & GRT6-1 & 0.30 & 0.30 & 0.6 & 8 \\
\hline 3 & GRT6-2 & 0.30 & 0.30 & 0.6 & 12 \\
\hline 4 & GRT9-1 & 0.45 & 0.45 & 0.9 & 8 \\
\hline
\end{tabular}

\subsection{Thermogravimetric Analysis (TGA)}

Perkin-Elmer (model TGA 7) was used with heating rate $20^{\circ} \mathrm{C}$ per minute in a controlled environment, the amount and rate of change in the weight of epoxy, hardener and epoxy-hardener can be measured. TGA was conducted to predict on thermal stability and weight loss due to decomposition and oxidation.

\subsection{Fire test}

Bunsen burner test and fire furnace test were conducted. Bunsen burner test was conducted to examine the ability of the char to resist heat transfer from direct fire. Three thermocouples were placed on the samples to obtain their temperature profile. All the samples were tested for 1 hour according to ASTM E119. Bunsen burner was used to bombard the samples from a distance of $7 \mathrm{~cm}$.

For fire furnace test, all the samples will be placed on a steel sheet and fire brick in Carbolite electric furnace to be heated up progressively. Temperature in the Carbolite furnace was increased from ambient temperature to $800^{\circ} \mathrm{C}$ with the rate of $26^{\circ} \mathrm{C} / \mathrm{min}$. After reaching the maximum temperature, it needs to be remained at the same temperature for an hour before the samples cooled to room temperature [5]. From the electric furnace fire test, the physical properties of the char were obtained.

\subsection{Scanning Electron Microscope and Energy Dispersive X-Ray Spectroscopy (SEM-EDS)}

Scanning Electron Microscope (SEM) is a highresolution imaging surface microscope, it will be used to study the surface morphologies of the coating and char layers. It is also used to analyse the elemental composition of fibres, coating and char. SEM-EDS analysis provides qualitative and quantitative analysis of elemental composition. In this project, coated sample and char was tested by SEM and EDS analysis.

\section{Results and discussions}

\subsection{Thermal Stability}

TGA analysis was done to acquire residual weight and degradation temperature for each intumescent coating formulation. The samples of different fibre weight and length of hybrid fibre reinforced intumescent coatings' TGA curve is shown in Fig. 1. Interestingly, all of the samples illustrate the similar trend of curve.

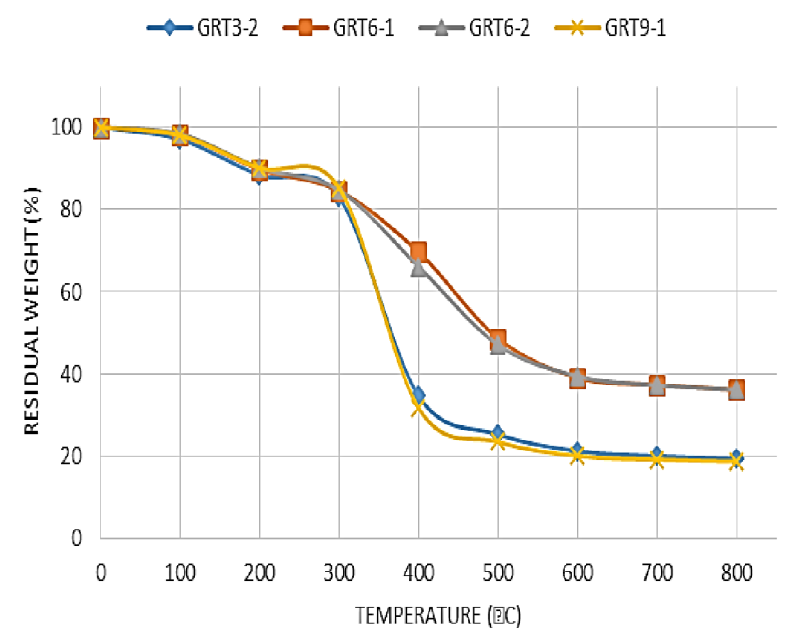

Figure 1. TGA curve of residual weight versus temperature

From the curve obtained, there are three significant changes in the slopes. All of the samples had undergone three phases before they fully degraded. For GRT3-2 and GRT9-1, phase 1: between $50^{\circ} \mathrm{C}$ to $230^{\circ} \mathrm{C}$, phase 2: $231^{\circ} \mathrm{C}$ to $400^{\circ} \mathrm{C}$ and phase $3: 401^{\circ} \mathrm{C}$ to $800^{\circ} \mathrm{C}$. On the other hand for GRT6-1 and GRT6-2, phase 1: $50^{\circ} \mathrm{C}$ to $300^{\circ} \mathrm{C}$, phase $2: 301^{\circ} \mathrm{C}$ to $500^{\circ} \mathrm{C}$ and phase $3: 501^{\circ} \mathrm{C}$ to $800^{\circ} \mathrm{C}$. At first phase, the weight loss was affected by the loss of small molecules and non-volatilized solvent [12]. On the second phase, the temperature decrease dramatically due to decomposition of main coating's ingredients [7]. Finally, the decomposition of EG induces the drop of temperature on the third phase. On the other hand, in the third phase, there is an interaction between EG and APP to form char structure due to their close decomposition temperature [13]. This trend verifies three stages in degradation process which are water elimination, degradation and residual process [14].

From the analysis, the residual weight increase by the increment in fibre weight percentage and fibre length. After the samples are burned up to $800^{\circ} \mathrm{C}$, the residual weight of GRT3-2, GRT6-1, GRT6-2 and GRT9-1 are $19.37,36.15,36.19$ and $18.70 \mathrm{wt} \%$, respectively. Among all, GRT6-2 yielded the highest residue weight. High residual weight indicated a good intumescent coating as it gave the greatest fire protection to the steel.

However, too much fibre weight affected the residual weight of the intumescent coating. This was shown by GRT9-1, which has the highest fibre weight but yielded the lowest residual weight. The addition of too much fibre weight reduced the epoxy composition in the intumescent coating formulation. Epoxy plays important role in flame retardant performance [15]. Reduction of 
the epoxy composition due to high amount of fibre had affected the coating's performance.

On the other hand, both formulations having intermediate fibre weight produced higher residual weight compared to other formulations. The coating with the highest residual weight posed good intumescent coating behaviour where the anti-oxidation could be enhanced at high temperature [13]. This is due to the reason that high residue means high remaining char. High char results in good mechanical resistance and high thermal stability [1].

\subsection{Fire Resistant Performance}

Bunsen burner test was conducted to characterize the formation of char and the reaction of the intumescent coating towards heat. It was conducted based on ASTM E-119. The changes of temperature at the back side of the steel plates coated with four different formulations after bombarded with $1000^{\circ} \mathrm{C}$ fire for 60 minutes recorded by AMS-850 data logger are presented in Fig. 2.

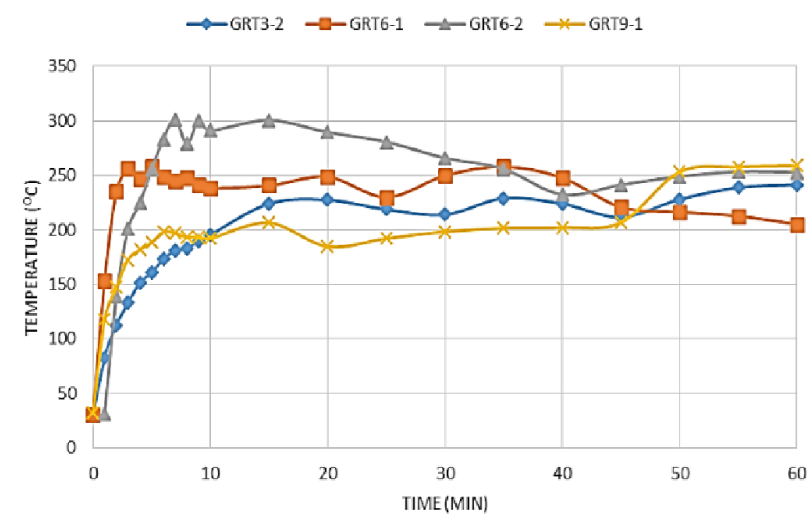

Figure 2. Evolution of temperature on the back side of steel plates of different hybrid fibre reinforced intumescent coatings.

After 10 minutes of heat exposure, the temperature of each formulation reached to their highest temperature and the temperature remains nearly constant for the next 50 minutes. The presence of hybrid fibre that do not degrade or deform at high temperature made the steel temperature maintained at constant value [11]. Moreover, denser structure produce during the fire test also increase the insulation properties of the char. For the first 10 minutes, the temperature of the substrates temperature of GRT3-2, GRT6-1, GRT6-2 and GRT9-1 increase up to $200^{\circ} \mathrm{C}$, $250^{\circ} \mathrm{C}, 290^{\circ} \mathrm{C}$ and $196^{\circ} \mathrm{C}$ respectively. High fibre content could withstand high temperature as Rockwool fibre and glass wool fibre also have high degradation temperature [16-17].

Nevertheless, at the end for the fire test, the temperature at the back side of the steel had changed. GRT6-1 had achieved the highest thermal insulation effect which was $197.6^{\circ} \mathrm{C}$. It was followed by GRT3-2 $\left(241.5^{\circ} \mathrm{C}\right)$, GRT6-2 $\left(250.0^{\circ} \mathrm{C}\right)$ and GRT9-1 $\left(258.8^{\circ} \mathrm{C}\right)$. Again, the reduction of epoxy composition in the samples because of high fibre content may affect the fire retardant performance as epoxy contributes partly towards it [18]. Furthermore, the crack produced on the surface of the coating due to high viscosity caused by fibre also produce large void hence lower down the fire retardancy of the coatings [19].

\subsection{Char expansion and weight loss}

All samples of intumescent coatings fire retardant hybrid fibre reinforced were fired in a fire furnace to $800^{\circ} \mathrm{C}$ for 1 hour. The samples were allowed to intumesce freely in furnace as furnace fire simulates a fire incident in a confined space $[5,7]$. The expansion and the weight loss of all samples with different fibre weight and length were evaluated. The thickness of the samples was measured by using vernier caliper. The char expansion and weight loss was measured by ruler and electronic weight scale respectively.

The char expansion and percentage of increment in char expansion were measured and shown in TABLE 3. Char expansion of the intumescent coating samples improved as the weight percentage was increased. It can be seen on the samples that have same fibre length but different in fibre weight. GRT3-2 with $0.3 \%$ hybrid fibre weight percentage has lower char expansion compared to GRT6-2 which contained $0.6 \%$ hybrid fibre weight percentage with $178.4 \%$ in difference. In addition, GRT91 has $196.1 \%$ of increment in char expansion which had improved $76.9 \%$ from GRT6-1.

Table 3. Char expansion and weight loss of hybrid fibre intumescent coating after $800^{\circ} \mathrm{C}$ fire test.

\begin{tabular}{|c|c|c|c|c|}
\hline No. & Samples & $\begin{array}{c}\text { Char } \\
\text { expansion } \\
\text { (times, X) }\end{array}$ & $\begin{array}{c}\text { Char } \\
\text { expansion } \\
(\%)\end{array}$ & $\begin{array}{c}\text { Weight loss } \\
(\%)\end{array}$ \\
\hline 1 & GRT3-2 & $2.56 \mathrm{X}$ & 156.4 & 10.26 \\
\hline 2 & GRT6-1 & $2.19 \mathrm{X}$ & 119.2 & 14.26 \\
\hline 3 & GRT6-2 & $4.35 \mathrm{X}$ & 334.8 & 14.08 \\
\hline 4 & GRT9-1 & $2.96 \mathrm{X}$ & 196.1 & 19.21 \\
\hline
\end{tabular}

Similar behaviour was observed with increment of fibre length, as the percentage of char expansion also increased. GRT6-1 and GRT6-2, which had different fibre length increased the char expansion by $119.2 \%$ and $334.8 \%$ respectively. The long fibre length make the tangle structure loose up hence allow the air pocket to develop in the char during the reaction of intumescent. On contrary, the increment of fibre length reduced the percentage of weight loss. It can be seen when GRT6-2 is compared to GRT6-1. Weight of char reduced due to materials lost in fire. GRT6-2 produced the most char yield and low weight lost compare to the coating of similar fibre weight. The lower is the weight loss; the bigger is the available amount of materials to protect the substrate [6].

The addition of hybrid fibre into fire retardant intumescent coating produce better fire protection due to less weight loss, lower and denser char expansion. It is way better compare to fire retardant intumescent coating 
without any filler. Previous study shows that control formulation with the same basic composition have high expansion [6]. Without any filler, the char resulted in fluffier char structure and many large pores were founded. Since more air passage exist in the control formulation, the fire can be easily penetrated to the substrate compare to close packed char structure of hybrid fibre intumescent coating.

However at $800^{\circ} \mathrm{C}$, the visual inspection showed that all the samples have like ash burn on the surface of the char. All of them were oxidized at high temperature.

\subsection{Coating and Char Morphology}

The hybrid fibre of Rockwool and glass wool fibre were intact and fully immersed in the coatings as shown in Fig. 3. It was confirmed as a result of low speed mixing [7] and can be seen clearly in Fig. 3(a).

GRT6-1 which is intumescent coating fire retardant hybrid fibre reinforced with $0.6 \%$ fibre weight percentage produce much crowded and dense char structure as shown in Fig. 3(d). Similar pattern is shown by GRT6-2 char, which produced dense and crowded char as in Fig. 3(f). According to [20], the crowded structure produced becomes barrier for holes formation, which was normally created when the blowing agent react against fire the voluminous carbonaceous char. Due to increase in fibre percentage, the char yield also increased. The crowded char were promoted by the hybrid fibre and bigger pores were filled up hence reduced the size of microscopic voids [11]. A crowded and dense char structure was developed by big diameter of glass wool fibre while smaller diameter of Rockwool fibre produced dense structure [7]. Therefore, the increment of the fibre weight and length resulted in greater char insulation.

It is clear that there are holes at charred surface of samples compared to coating surface. The holes were mainly due to eruption of gases which lead to swelling of intumescent coating [21]. The hybrid fibre act as heat insulators and limit heat transfer from the heat source and prevent the diffusion of the gaseous degradation products to the combustion zone [21].

Rockwool fibre and glass wool fibre as fire resistant fibres provide good mechanical structure to the char. The fibres preferentially form link or bridge with other intumescent materials which called as char bonded [22].

GRT3-2 and GRT9-1 substantially degraded at $800^{\circ} \mathrm{C}$. It can be seen in Fig. 3(g-h) that there are some voids on the coating and char. Low strength of char is associated with voids which can cause crack during heating hence lead to a reduction in the fire protection efficiency [11, 23]. However, fibres form was maintained at $800^{\circ} \mathrm{C}$ hence helped to provide structure and strengthen the char.

\subsection{Elemental analysis results}

Fig. 4. and Fig. 5. show EDS analysis on coatings and char. Similar trend was shown as the samples been compared. The concentration of oxygen increase and carbon concentration decrease as coatings transform into char in fire. This is because the samples were oxidized and carbon was burnt during combustion process. On this experiment, it was found that GRT6-2 contained the highest carbon concentration and the lowest oxygen concentration on the coating. For the carbon concentration in the coating, GRT6-2 was followed by GRT6-2, GRT9-1 and GRT3-2. After the coatings were burnt into char, the highest carbon content left was in GRT3-2 followed by GRT6-2, GRT9-1 and GRT6-1.

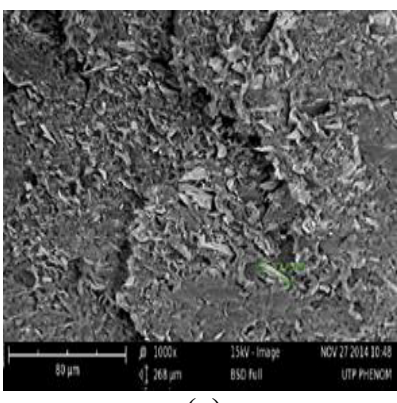

(a)

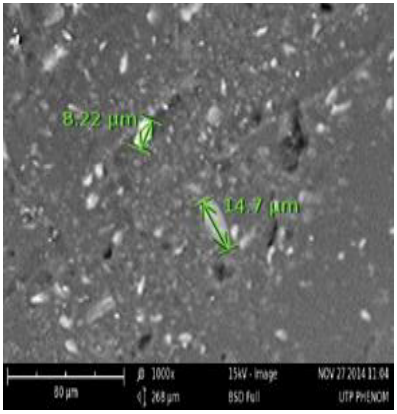

(c)

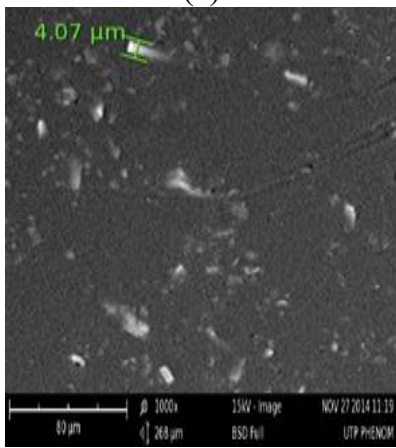

(e)

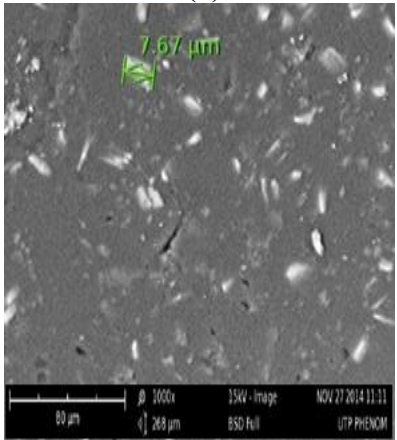

(g)

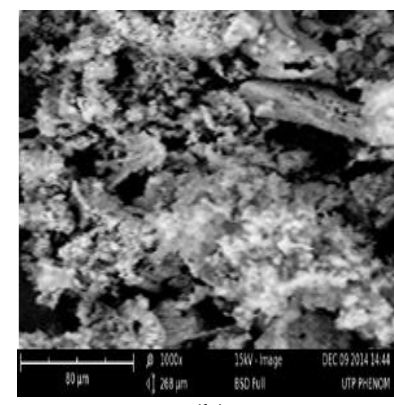

(b)

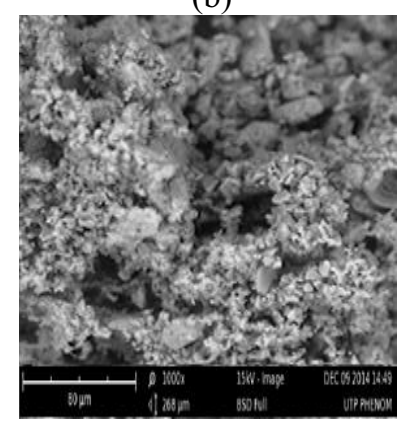

(d)

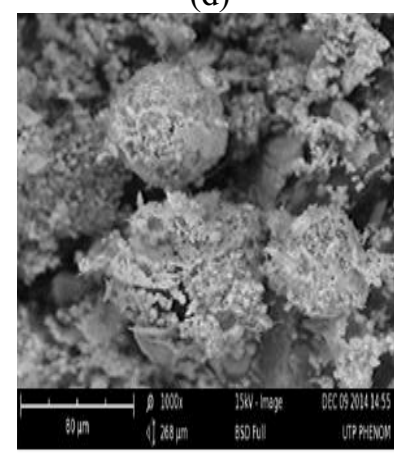

(f)

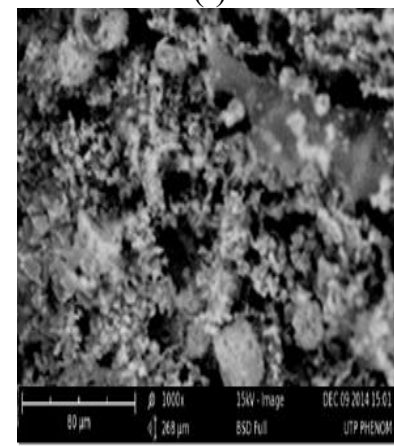

(h)
Figure 3. SEM images across the coatings and char showing the role played by hybrid fibres at $1000 \mathrm{X}$ magnification after $800^{\circ} \mathrm{C}$ fire test (a) GRT3-2 coating (b) GRT3-2 char (c) GRT6-1 coating (d) GRT6-1 char (e) GRT6-2 coating (f) GRT6-2 char (g) GRT9-1 coating (h) GRT9-1 char 
On contrary to oxygen concentration, it increased as the coatings burnt into char. The highest oxygen content in char was GRT6-2. The rank was GRT6-2 > GRT9-1 > GRT6-1 and GRT3-2. GRT9-1 shows that it was rich in oxygen content where it contains the highest oxygen concentration in coating.

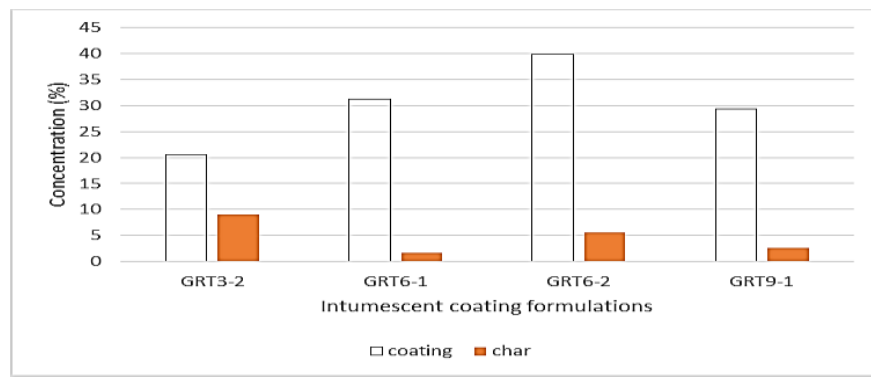

Figure 4. Carbon concentration for the coatings and chars of various formulations

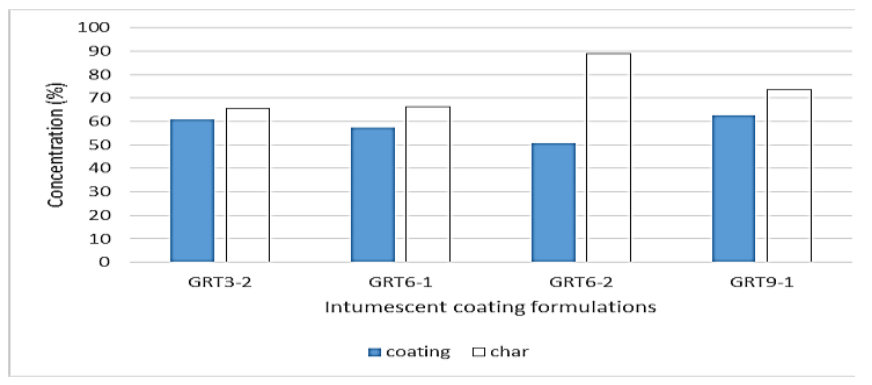

Figure 5. Oxygen concentration for the coatings and chars of various formulations

Furthermore, aluminium element also existed in all the samples of intumescent coatings fire retardant which have been reinforced by hybrid fibre (Rockwool fibre + glass wool fibre). The element found, offers a better fire protection to the substrate [11].

\section{Conclusions}

The highest residual weight as determined through TGA was achieved by GRT6-2 with $36.19 \%$ followed by GRT6-1 (36.12\%). This means, GRT6-2 showed better anti-oxidation compared to the other formulations. On the other hand, direct fire test by Bunsen burner had the highest residual weight coming from GRT3-2 followed by GRT6-2, GRT6-1 and GRT9-1.

GRT6-1 had achieved the highest thermal insulation effect and gave steel temperature of $197.6^{\circ} \mathrm{C}$ after an-hour Bunsen burner test. SEM analysis confirmed that fibres form was maintained at $800^{\circ} \mathrm{C}$ hence helped to provide structure, which strengthen the char.

The research found that an optimum fibre amount and long-fibre promoted production of high amount of char to protect the substrate from fire, efficiently. Therefore, it is concluded that the intermediate fibre weight, which was $0.6 \%$ with long fibre length at $12 \mathrm{~mm}$, was the best formulation for hybrid fibre reinforced intumescent coating as it consistently yielded good results in all test conducted.

\section{References}

1. M. Jimenez, S. Duquesne, S. Bourbigot, Thermochim. Acta, 449, 16-26 (2006)

2. T. A. Roberts, L. C. Shirvill, K. Waterton, I. Buckland, Process Saf. Environ., 88, 1-19 (2010)

3. K. M. Butler, Am. Chem. Soc. (1997)

4. J. Bisschoff, University of Pretoria (2000)

5. N. Amir, F. Ahmad, P. S. M. Megat-Yusoff, Adv. Mat. Res., 626, 504-508 (2013)

6. N. Amir, F. Ahmad, P. S. M. Megat-Yusoff, J. Appl. Sci., 11, 1678-1687 (2011)

7. N. Amir, F. Ahmad, P. S. M. Megat-Yusoff, Eng. eT, 6, 136-144 (2011)

8. N. Amir, W.M.S.W. Othman and F. Ahmad AIP Conf. Proc. 1669, 020062 (2015)

9. National Industrial Co, Chennai. [Online]. [Accessed 122 2014].

10. M. D. Durovic-Petrovic, European University (2013)

11. N. Amir, F. Ahmad, P. S. M. Megat-Yusoff, J. Appl. Sci., 23, 2459-2463 (2012)

12. J.-w. Gu, G.-c. Zhang, S.-l. Dong, Q.-y. Zhang, J. Kong, Surf. Coat. Tech., 201, 7835-7841 (2007)

13. G. Li, G. Liang, T. He, Q. Yang, X. Song, Polym. Degrad. Stabil., 92, 569-579 (2007)

14. F. Ahmad, S. Ullah, M. S. Hamizol, J. Appl. Sci., 12, 2631-2635 (2012)

15. M. C. Yew, N. H. Ramli Sulong, Adv. Mater. Res., 168-170, 1228-1232 (2011)

16. http://www.sciencelab.com/msds.php?msdsId=99241 41. [Accessed 23 May 2014].

17. N. Ralph, Available: http://www.isoclad.co.uk/. [Accessed 225 2014].

18. C. Jiao, J. Zhuo, X. Chen, S. Li, H. Wang, J Therm. Anal. Calorim., 114, 253-259 (2013)

19. G. Wang, J. Yang, Surf. Coat. Tech., 206, 2146-2151 (2012)

20. J. W. Hanafin, D. C. Bertrand, US Patent (2000)

21. M. Kumar , M. Kumar, S. Arora, J. Indian Acad. Wood Sci., 10, 125-133 (2013)

22. B. Kandola, A. Horrocks, S. Horrocks, Fire Mater, 25, 153-160 (2001)

23. M. C. Yew, N. R. Sulong, Mater. Des., 34, 719-724 (2012) 